\title{
THE CITY NATURE CHALLENGE 2020
}

\author{
MARY KENNEDY*, DAVID IRELAND, \\ AND ANDREA HART
}

Dartmouth, NS

In April 2020, six areas in the Maritimes will participate in the international City Nature Challenge (CNC). This citizen science event sponsored by the Natural History Museum of Los Angeles and the California Academy of Sciences is organized locally by a number of keen naturalists and outdoor enthusiasts. The local objectives are simply to encourage people to get outdoors; to explore; to observe nature; to share observations; and to have fun.

Local activities and promotional information such as the Maritime CNC2020 poster (Fig 1) will be accessible on the Facebook page of CityNatureChallengeMaritimes.

The first CNC took place in 2016 in California with just two cities involved. It has grown exponentially since then, with 159 cities including the Halifax Regional Municipality competing in 2019. It is expected that over 250 cities from around the world will compete in 2020 to see who can make the most observations of nature, find the most species, and engage the most people.

The CNC competition takes place in two parts over the course of 10 days. First, nature observations (photos of wild plants and animals) are recorded. This is followed by a short period for these observations to be uploaded and identified by the iNaturalist community as best as possible before the challenge ends. The final numbers across three categories (total observations, total species, and total participants) are counted for each competing city/area project and winners are announced. The dates for 2020 are as follows: April 24-27 observation/ collection period; April 28 - May 3 final upload and identification period; May 4 winners announced.

The platform for sharing observations of wild flora and fauna is iNaturalist. In Canada, iNaturalist.ca is led by the Canadian Wildlife Federation, along with Parks Canada, NatureServe Canada, and the Royal Ontario Museum, all collaborating with iNaturalist.org. iNaturalist is a joint initiative of the California Academy of Sciences and the National Geographic Society.

\footnotetext{
* Author to whom correspondence should be addressed: cnc2019hrm@gmail.com
} 


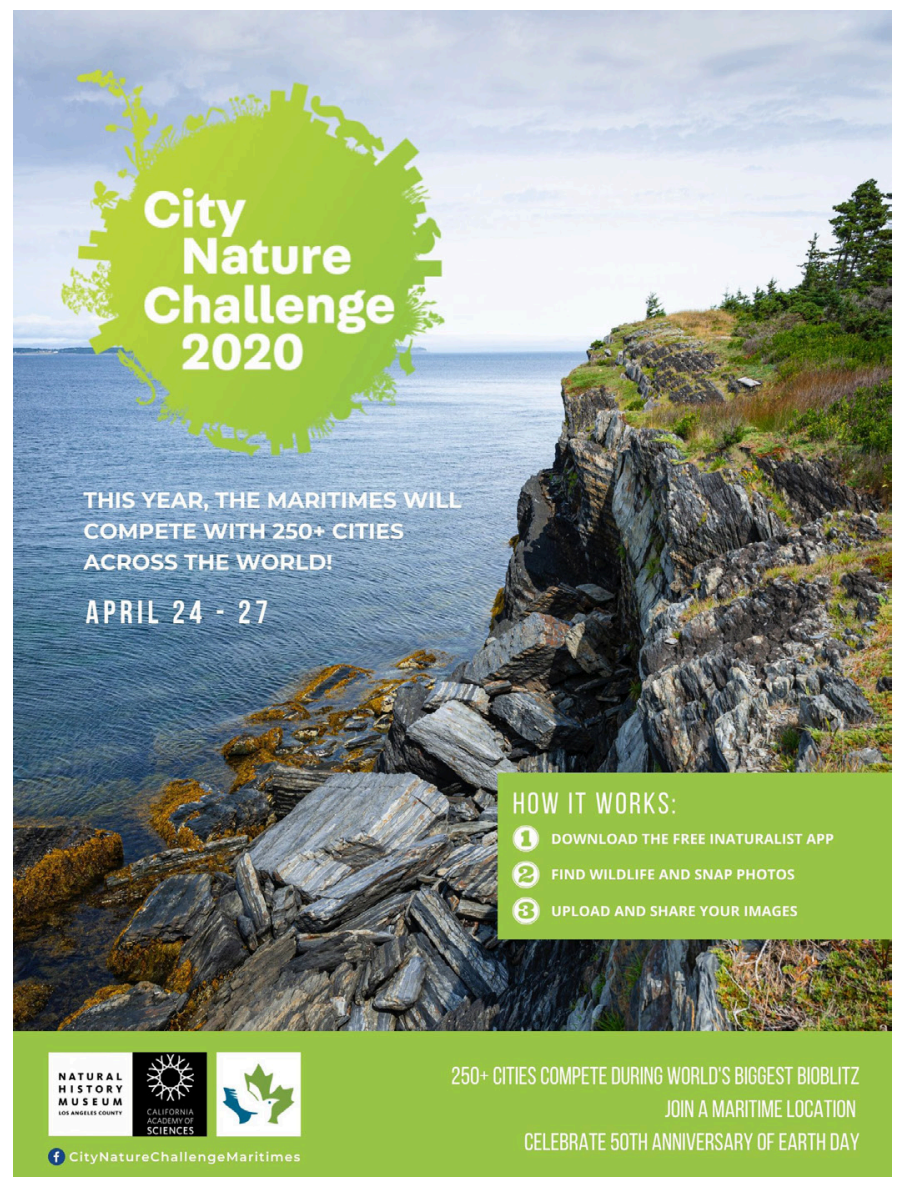

Fig 1 The $\mathrm{CNC} 2020$ poster for the six Maritime areas.

Registering the Maritimes to participate in the CNC is a simple way to introduce our community to iNaturalist. The timing of the event, April, may not be a prime time to assess the biodiversity of our region. It does, however, occur on the weekend following the 50th anniversary of Earth Day, April 22nd. This is an excellent opportunity for everyone to get outdoors after a long winter and record information about the natural history in our area. Observations at this time of year may highlight the fact that spring has arrived or is on its way. 
Maritimers across the region are concerned about climate change. Sharing observations with iNaturalist is one simple method to compile information required to understand and manage our resources, and to document environmental change. These observations will help verify species distribution or help fill temporal/spatial coverage. The City Nature Challenge 2020 is an excellent opportunity to learn how you can contribute, as a citizen scientist. Members of the NSIS are encouraged to participate, and also to ask their friends and colleagues to become involved too. Given the environmental challenges of climate change and other stresses, every recorded observation counts! 
